\title{
A Simple Method for Removing the Distortion of Image in Whole Sky Photographs of Clouds
}

\author{
By Takeshi Yamazaki and Choji Magono \\ Department of Geophysics, Hokkaido University, Sapporo \\ (Manuscript received 20 June 1970)
}

The whole sky photograph is frequently used to observe the horizontal distribution of clouds over a wide area. However, because the distortion of image in the whole sky photograph is extremely great except its center portion, it is usually difficult to imagine the actual cloud distribution from the photograph. In addition it is tedious to correct the distortion for many points in the image. Therefore, a simple method for removing the distortion from the whole sky photograph was required for the observation of horizontal cloud distribution.

It is known that if a developed negative film in a camera is illuminated under the same optical condition used in the original photograph, the illuminating light beams are reversed; in other words, they are directed to pass through the camera with the same angle at which the photograph was taken, and then the same image as the original object will be reproduced at the place of the object, in accordance with the reverse principle of light. Because this principle is applicable to the whole sky photograph, an undistorted image will be obtained on a photographic paper at a long distance from the camera, if the photographic paper is set at right angle to the axis of the camera.

A simple method for removing the distortion of image in whole sky photographs was attempted. The practical procedure was as follows. A whole sky camera with a lens of $8 \mathrm{~mm}$ focal length and the resulting developed negative film were used. The camera was of the fixed focal point type which covered objects farther than $2.5 \mathrm{~m}$.

The optical arrangement of the apparatus was as shown in Fig. 1. The rear wall of the camera was removed. The developed negative film was

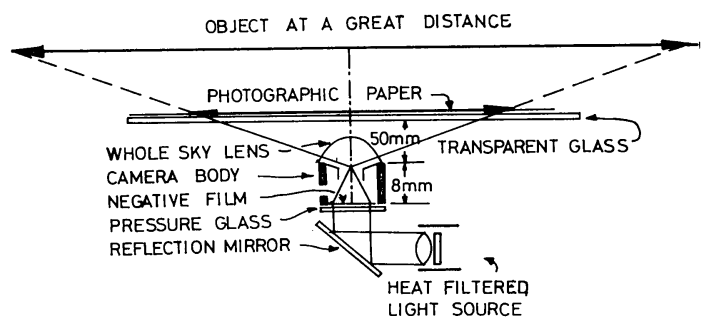

Fig. 1 Arrangement of apparatuses for correcting distortions in a whole sky photograph.

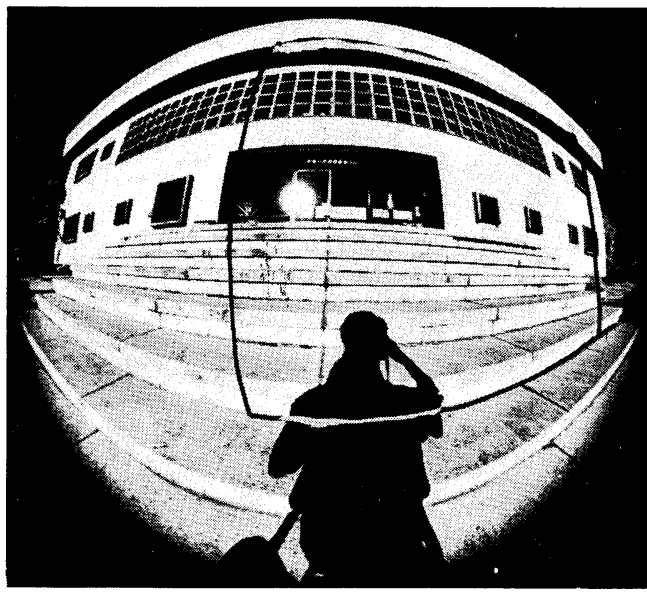

Fig. 2a A whole sky photograph of a front of a building.

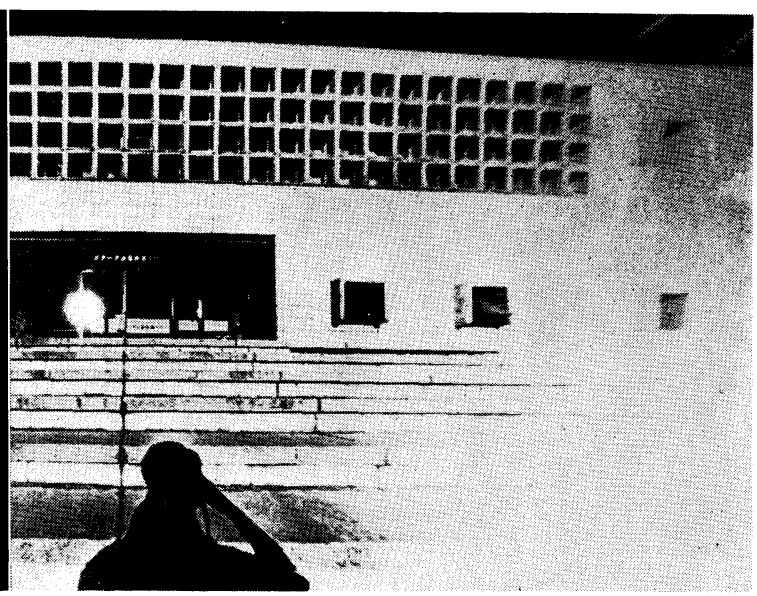

Fig. 2b Corrected photograph of the portion enclosed by lines in Fig. $2 \mathrm{a}$. 


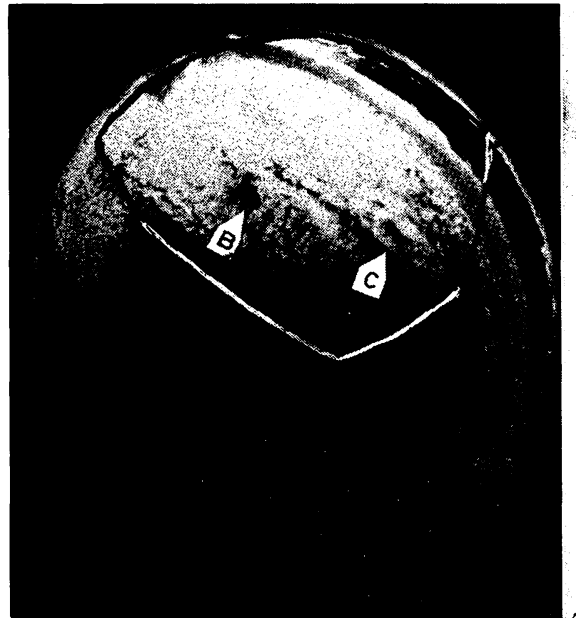

Fig. 3a A whole sky photograph of cirrus cloud.

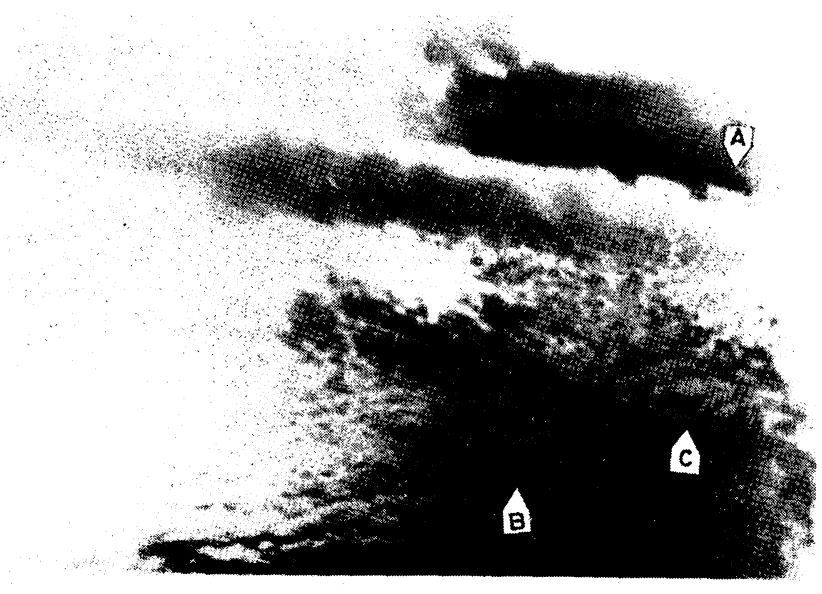

Fig. 3b Corrected photograph of the portion enclosed by lines in Fig. 3a. charged in the camera and it was fixed by a small transparent glass plate. Another large glass plate was also set at right angle to the axis of the camera, and a photographic caper of size $25 \times 30$ $\mathrm{cm}^{2}$ was put on the glass plate.

When the negative film was illuminated from bottom by heat filtered light at the state of iris $f$ 22 , undistorted image of the negative film was reproduced on the photographic paper, as illustrated in Figs. 2a and 2b. Fig. $2 a$ is an original whole sky photograph of a building, and Fig. 2b is the corrected photograph of the region enclosed by lines in Fig. 2a. It may be easily understood that the correction of distortion in the whole sky photograph was nearly perfect. It is also noticed that the apparent focussing of corrected image was fairly good, even if the photographic paper was set in a moderate distance of only $50 \mathrm{~mm}$ from the lens. This was because the effective diameter of the lens determined by its iris was as small as $0.3 \mathrm{~mm}$ in the reproducing projection; in other words, the photograph was taken by a kind of pinhole camera.

Figs. $3 a$ and $3 b$ show an example of the correction of image in a whole sky photograph of clouds of cirrus type which was taken in Sapporo on September 2, 1966. The area of Fig. 3b corresponds to that enclosed by lines in Fig. 3a. The points indicated by $A, B$ and $C$ in the figures show the corresponding places. It was considered that the cirrus type clouds were distributed horizontally in a thin layer, and the axis of the camera was pointed exactly vertically. Therefore, if the height of the cloud layer is known, their absolute size and horizontal distribution would be analysed, using Fig. $3 b$.

Fig. 4 shows rawin sonde data obtained by the Sapporo Meteorological Observatory on the same day. In the figure, it is seen that there was a temperature inversion layer at $400 \mathrm{mb}$ level, and this level was considerably humid, compared with the lower layers. Therefore it was considered that the cirrus type cloud layer was at $400 \mathrm{mb}$ level, and at least the cloud bottom was at the level. Based on this consideration, the size and location of the clouds were determined, then their horizontal distributions were traced on the map between

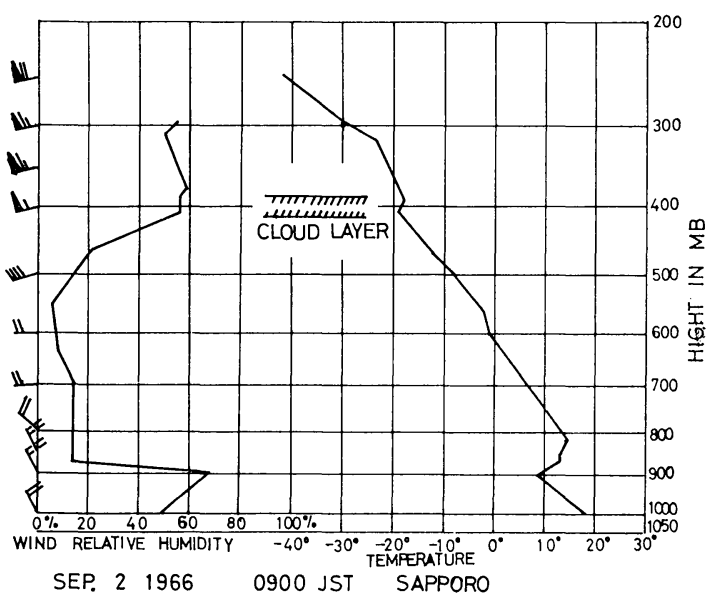

Fig. 4 Vertical distributions of wind, relative humidity and air temperature near the photographing time at Sapporo. 


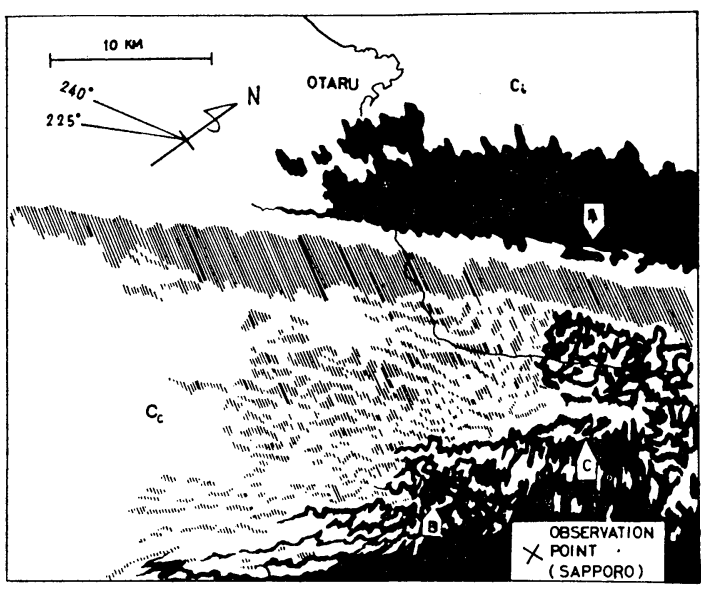

Fig. 5 Horizontal distribution of cirrus clouds over Sapporo and Otaru, determined from Figs. $3 a$ and $3 b$.

Sapporo and Otaru as shown in Fig. 5 where dark areas show cloudless area. The determination of direction was made by known ground marks in the original whole sky photograph of Fig. 3a.

In Fig. 5, it is seen that there was a big cloud band with width of about $3 \mathrm{~km}$ and many arrays of cirrocumuli with sizes of about $0.5-1 \mathrm{~km}$, and they were directed to $225^{\circ}$ in parallel. According to the rawin sonde data shown at the left end of
Fig. 4, the wind direction was about $240^{\circ}$ around the cloud level, but a vertical wind shear existed. It is noted that the direction of the band and arrays of cirrocumuli roughly agreed with the direction of the wind shear at the level. This is a reasonable result, considering the relation of cloud distribution with the wind system at the level, as reported by Malkus and Riehl (1964), and Magono, Kikuchi and Kajikawa (1967).

As seen in Figs. 2 and 3 the intensity of illumination was insufficient at the periphery portion of the photographs. In order to obtain a uniform exposure, some device is required in the illumination of the negative film or of the photographic peper.

Such a method based on the reverse principle of light and the pinhole camera effect is also useful to remove the distortion of image in the usual oblique cloud photograph.

\section{References}

Malkus, J.S. and H. Riehl, 1964: Cloud structure and distributions over tropical Pacific Ocean. Tellus, 16, 275-287.

Magono, C., Kikuchi and M. Kajikawa, 1967: Distribution of low-level rows and three dimensional analysis of cirrus clouds. J. Meteor. Soc. Japan, 45, 467-477.

雲の全天写真の歪の簡単な除去方法

山崎武, 孫 野 長 治

北大理学部, 地球物理学教室 